\title{
Pertussis-like syndrome associated with adenovirus presenting with hyperleukocytosis: Case report
}

\author{
Hakan Sarbay, ${ }^{1}$ Aziz Polat, ${ }^{1}$ Emin Mete, ${ }^{2}$ Yasemin Isik Balci, ${ }^{1}$ Mehmet Akin ${ }^{1}$ \\ ${ }^{1}$ Department of Pediatric Hematology and Oncology, Pamukkale University Faculty of Medicine, Denizli, Turkey \\ ${ }^{2}$ Department of Pediatric Allergy, Pamukkale University Faculty of Medicine, Denizli, Turkey
}

\begin{abstract}
Adenovirus is an infectious viral agent that causes variety of clinical presentations such as respiratory disease, conjunctivitis, and gastroenteritis. Hepatitis, pancreatitis, myocarditis, encephalitis, and disseminated infection are primarily seen in immunocompromised patients. Rarely, adenovirus infection can present with pertussis-like syndrome. Described here is case of pertussis-like syndrome associated with adenovirus presenting with hyperleukocytosis.
\end{abstract}

Keywords: Adenovirus; hyperleucocytosis; pertussis-like syndrome.

A denovirus, is a non-enveloped, double-strand DNA virus consisting of seven sub-species (A, B, C, D, E, F, G), and 52 different serotypes [1]. Adenovirus which is resistant against conditions of external environment is transmitted through respiratory tract, direct contact, and collectively used objects [2]. In clinical practice adenovirus most frequently causes respiratory tract infections, and gastroenteritis. Besides it can present with various clinical manifestations as pharyngoconjunctival fever, hemorrhagic cystitis, epidemic keratoconjunctivitis, myocarditis, hepatitis, encephalomyelitis, and invagination. In infants, and immunocompromised patients adenovirus infections can be seen [3]. Rarely adenovirus may present with pertussis-like syn- drome characterized by paroxysmal fits of coughing $[4,5]$. In the pediatric age group the most frequent cause of hyperleucocytosis is acute leukemia [6]. Among infectious diseases, in pertussis infection hyperleucocytosis invariably accompanied by lymphocytosis can be seen [7]. In this article, a patient with pertussis-like syndrome caused by adenovirus who presented with hyperleuocytosis has been reported.

\section{CASE REPORT}

A 9-month-old female patient was brought to a health institute with complaints of coughing persisting for 2 weeks. Her hematologic tests revealed the presence of hyperleucocytosis $\left(107.000 / \mathrm{mm}^{3}\right)$, 
TABLE 1. Whole blood cell count, and peripheral smear results of the patient $x$

\begin{tabular}{lccccccc} 
Day & $\begin{array}{c}\text { WBC } \\
\left(/ \mathrm{mm}^{3}\right)\end{array}$ & $\begin{array}{c}\text { Hemoglobin } \\
(\mathrm{gr} / \mathrm{dl})\end{array}$ & $\begin{array}{c}\text { Platelet } \\
\left(/ \mathrm{mm}^{3}\right)\end{array}$ & $\begin{array}{c}\text { Neutrophil } \\
(\%)\end{array}$ & $\begin{array}{c}\text { Lymphocyte } \\
(\%)\end{array}$ & $\begin{array}{c}\text { Monocyte } \\
(\%)\end{array}$ & $\begin{array}{c}\text { Eosinophil } \\
(\%)\end{array}$ \\
\hline 1. day & 102.900 & 10.6 & 797.000 & 26 & 72 & 2 & - \\
3. day & 66.680 & 10.9 & 761.000 & 22 & 72 & 4 & 2 \\
7. day & 42.290 & 10.9 & 678.000 & 18 & 78 & 2 & 2 \\
\hline
\end{tabular}

WBC: Whole blood cell.

and consequently she was referred to us with the initial diagnosis of leukemia. Her history revealed the presence of vomiting, and diarrhea in addition to her complaints of coughing within the first week. She hadn't been vaccinated. Her personal, and family history were unremarkable. Her general health state was evaluated as moderately well. Her oropharynx was hyperemic, and crepitant rales were heard bilaterally over basal lobes of her lungs. The liver was palpable $2 \mathrm{~cm}$ below the costal margin. Some of her laboratory values were as follows: hemoglobin: 10.6 gr/dl, WBC: 102.900/ $\mathrm{mm}^{3}$, platelets: $797.000 /$ $\mathrm{mm}^{3}$, normal hepatic, and renal function test results; uric acid: $2.5 \mathrm{mg} / \mathrm{dl}$, and LDH: $386 \mathrm{U} / \mathrm{L}$. Results of peripheral smear analysis were as follows : neutrophils: $26 \%$, lymphocyte: $72 \%$, monocyte: $2 \%$, absence of atypical cells, and blast cells. Hypochromic, and microcytic erythrocytes and anisocytosis were detected. Abundant clusters of platelets were seen. On chest X-ray, dimensions of mediastinum were within normal limits, and infiltration in the right paracardiac region was seen. The patient was started on intravenous fluid therapy, and nebulized salbutamol was administered. PPD test - negativity was noted. Levels of immunoglobulins, C3, and C4 were within normal limits. Polymerase chain reaction (PCR) performed with throat swab, and respiratory tract panel realized for adenovirus infection yielded positive results. On pertussis culture media any bacterial growth was not observed. PCR test could not detect any evidence of pertussis infection. Respiratory tract infection caused by an adenovirus, and hyperleucocytosis were contemplated. On 3. day of her hospitalization WBC was $66.680 / \mathrm{mm}^{3}$. During follow-up of the patient, her respiratory symptoms, and complaints of coughing regressed at the end of the first week of her hospitalization. On 7. day of her hospital stay WBC was $42.290 / \mathrm{mm}^{3}$. Whole blood cell counts, and results of her peripheral smear are shown in Table 1. Complaints of the patient regressed, and her clinical problems resolved during her follow-up, and consequently she was discharged with prescription of a vacination plan.

\section{DISCUSSION}

Classical whooping cough infection courses with paroxysmal fits of coughing, vomiting after coughing, deep inspirium, and intermittent symptoms of coughing lasting longer than 28 days up to 3 months [7]. Adenovirus infections most frequently present with manifestations of respiratory tract infections, and gastroenteritis [3]. In our patient coughing episodes lasted for 3 weeks, and in the first week diarrhea, and vomiting accompanied complaints of coughing.

In the pediatric age group acute leukemias are the most frequent causes of hyperleukocytosis [6]. Apart from leukemias, infections, drugs, bleeding, hypersensitivity reactions, splenectomy, and solid tumors induce leukemoid reaction leading to development of hyperleukocytosis. However hyperleukocytosis secondary to absolute lymphocytosis is seen in pertussis, tuberculosis, and viral infections. Among viral infections, EBV infection is the most frequent cause of hyperleukocytosis [8]. Whole blood cell count of our patient demonstrated hyperleukocytos, anemia, and reactive thrombocytosis. Lymphocytes were seen in $72 \%$ of peripheral smears. Morphologic examination of leukocytes did not reveal presence of atypical cells, and blastocytes. Detection of hypochromia, microcytosis, and anocytosis suggested the presence iron deficiency anemia. Tests to be made 
to clarify the etiology of postinfectious anemia were planned. Development of thrombocytosis was presumably attributed to anemia, and infection.

Apart from Bordetella pertussis infection the manifestations of pertussis-like coughing can be encountered during the course of infections caused by Chlamydiae pneumoniae, Chlamydiae trochomatis, Mycoplasma pneumoniae, adenoviruses, and Bordetella branchiseptica. In a study on 149 patients who presented with clinical manifestations of pertussis, the most frequently detected infectious agents, apart from Bordetella pertussis were adenoviruses, Parainfluenza, Mycoplasma pneumoniae, and RSV. In this study, adenoviruses, and Mycoplasma pneumoniae were detected in 3, and 1.3\% of the cases, respectively [4]. In patients presenting with clinical manifestations of pertussis where Bordetella pertussis can not be isolated or can not be confirmed serologically, investigation for infectious agents as Mycoplasmae, Chlamydiae, and adenoviruses has been recommended [9].

Gold standard for the diagnosis of pertussis is detection of bacterial growth on culture which has a $100 \%$ specificity. Its sensitivity changes depending on many factors as stage of the disease, initiation of antimicrobial treatment, sampling method, quality of the material used for sampling, conditions of delivery of the sample to the laboratory, and experience of the laboratory, and ranges between 12, and 60 percent. PCR is another method used for the diagnosis of pertussis. The World Health Organization recommends combined use of antibiograms, and PCR technique for the diagnosis of pertussis. Sensitivity, and specificity of PCR method have been indicated as $70-99 \%$, and $86-100 \%$, respectively [10]. In our patient bacterial growth was not detected on pertussis culture media. PCR test yielded negative results. PCR respiratory tract panel revealed presence of adenovirus, and absence of Mycoplasma pneumoniae, and RSV.

Although the patient presented to our clinic with pertussis-like coughing, complaints of vomiting, and diarrhea at the beginning of the disease, shorter duration of the coughing when compared with whoopig cough, and in consideration of laboratory test results, presumptive diagnosis of pertussis-like syndrome secondary to adenovirus infection, and hyperleucocytosis were made. Since all her necessary vaccinations were not performed, and diagnostic laboratory methods were not $100 \%$ sensitive, Bordatella infection could not be ruled out conclusively. In conclusion, in patients presenting with clinical manifestations of pertussis, and hyperleucocytosis, if especially etiologic agent can not be cultivated, then adenovirus infections should be considered in the differential diagnosis, and relevant investigations should be carried out.

\section{Conflict of Interest: None declared.}

Financial Disclosure: The authors declared that this study has received no financial support.

\section{REFERENCES}

1. American Academy of Pediatrics. Adenovirus enfeksiyonlar1. İçinde: Pickering LK, Baker CJ, Long SS, McMillan J, (eds) Redbook: 2006 enfeksiyon hastalıkları komite raporu. 27. bask1. Elk Grove Village: IL American Academy of Pediatrics 2006:211-2.

2. Henquell C, Boeuf B, Mirand A, Bacher C, Traore O, Déchelotte $\mathrm{P}$, et al. Fatal adenovirus infection in a neonate and transmission to health-care workers. J Clin Virol 2009;45:345-8. Crossref

3. Behrman RE, Kliegman RM, Jenson HB. Nelson textbook of pediatrics. 18 th ed. Pennsylvania: Saunders 2007;259:1393-4.

4. Wirsing von König $\mathrm{CH}$, Rott $\mathrm{H}$, Bogaerts H, Schmitt HJ. A serologic study of organisms possibly associated with pertussis-like coughing. Pediatr Infect Dis J 1998;17:645-9. Crossref

5. Ferrer A, Calicó I, Manresa JM, Andreu A, Moraga F, Valle I. Microorganisms isolated in cases of pertussis-like syndrome. [Article in Spanish] Enferm Infecc Microbiol Clin 2000;18:433-8. [Abstrac]

6. Porcu P, Cripe LD, Ng EW, Bhatia S, Danielson CM, Orazi A, et al. Hyperleukocytic leukemias and leukostasis: a review of pathophysiology, clinical presentation and management. Leuk Lymphoma 2000;39:1-18. Crossref

7. Munoz FM. Pertussis in infants, children, and adolescents: diagnosis, treatment, and prevention. Semin Pediatr Infect Dis 2006;17:14-9. Crossref

8. George TI. Malignant or benign leukocytosis. Hematology Am Soc Hematol Educ Program 2012:475-84.

9. American Academy of Pediatrics, Red Book. Pertussis 2003.

10. ID_2010May_Pertussis-Diagnostics-Brochure.http:// www.aphl.org/AboutAPHL/publications/Documents/ ID_2010May_Pertussis-Diagnostics-Brochure.pdf (son erişim tarihi: 06.01.2014). 